\title{
Interleukin-7 Stimulates Secretion of S100A4 by Activating the JAK-STAT Signaling Pathway in Human Articular Chondrocytes
}

\author{
Raghunatha R. Yammani, PhD ${ }^{1}$, David Long, BS ${ }^{1}$, and Richard F. Loeser, MD1 \\ ${ }^{1}$ Section of Molecular Medicine, Wake Forest University School of Medicine, Medical Center Blvd, \\ Winston-Salem, NC 27157, USA
}

\section{Abstract}

Objective-S100A4 has been shown to be increased in OA cartilage and to stimulate chondrocytes to produce MMP-13 through activation of the receptor for advanced glycation end products (RAGE). The aim of this study was to understand the mechanism of S100A4 secretion by chondrocytes.

\begin{abstract}
Methods-Human articular chondrocytes isolated from ankle cartilage were stimulated with $10 \mathrm{ng} / \mathrm{ml}$ of IL-1 $\beta$, IL-6, IL-7 or IL-8. Cells were pretreated with either a JAK-3 inhibitor, brefeldin-A, or cycloheximide. Immunoblotting with phospho-specific antibodies was used to determine the activation of signaling proteins. Secretion of S100A4 was measured in the conditioned media by immunoblotting and MMP-13 was measured by ELISA.
\end{abstract}

Results-Chondrocyte secretion of S100A4 was observed after treatment with IL-6 or IL-8 but was much greater in cultures treated with equal amounts of IL-7 and was not observed with IL- $1 \beta$. IL-7 activated the JAK/STAT pathway with increased phosphorylation of JAK-3 and STAT-3 leading to increased production of S100A4 and MMP-13. Overexpression of a dominant negative RAGE construct inhibited IL-7 mediated production of MMP-13. Pretreatment of chondrocytes with a JAK-3 inhibitor or with cycloheximide blocked the IL-7 mediated secretion of S100A4. However, pretreatment of chondrocytes with brefeldin-A did not.

Conclusions-IL-7 stimulates chondrocyte secretion of S100A4 via activation of JAK/STAT signaling and then S100A4 acts in an autocrine manner to stimulate MMP-13 production via RAGE. Since both IL-7 and S100A4 are upregulated in OA cartilage and can stimulate MMP-13 production by chondrocytes, this signaling pathway could contribute to cartilage destruction during the development of OA.

\begin{abstract}
S100 proteins are acidic low molecular weight calcium binding proteins that are only found in vertebrates and are expressed in many tissues in humans (1). The S100 protein family consists of 21 known members and is considered as one of the largest subgroups of the EFhand calcium binding protein family (1). S100 proteins regulate numerous intracellular functions including protein phosphorylation, enzyme activation, cell motility, cell growth and differentiation, and calcium homeostasis (2). Interestingly, S100 proteins are also known to have extracellular functions. Studies have shown S100B is released into the extracellular environment by neuronal cells and stimulates neurite extension and promotes cell survival (3). The extracellular functions of S100 proteins are attributed to their ability to be released from cells and interact with cell surface receptors including the receptor for advanced glycation end-products (RAGE) (4). Recent studies in chondrocytes have shown
\end{abstract}

Address for correspondence and reprint request to Raghunatha R. Yammani, PhD, Section of Molecular Medicine, Wake Forest University School of Medicine, Medical Center Blvd, Winston-Salem, NC 27157, USA. E. mail: ryammani@wfubmc.edu. 
that when added extracellularly, S100 proteins stimulated expression of MMP-13 (5) and promoted chondrocyte hypertrophy (6) through stimulation of RAGE signaling.

S100A4 is a member of the S100 family that was originally isolated as a gene differentially expressed in mouse adenocarcinoma cells (7) and subsequently found in other tissues (8). Recent studies have identified S100A4 in cartilage and have shown it to be upregulated in tissues from subjects with OA or RA $(5,9)$. Like other members of the S100 family, S100A4 exerts intra- and extracellular effects. With respect to its intracellular targets, S100A4 binds the p53 tumor suppressor and regulates its functions (10). S100A4 also interacts with the heavy chain of non-muscle myosin II and plays an active role in cell motility and adhesion in metastatic tumor cells (11). When applied extracellularly, S100A4 acts as a potent cytokine that stimulates neurite outgrowth in astrocytes (12) and angiogenesis in endothelial cells (13).

In addition, S100A4 is also suggested to play an important role in matrix remodeling (14). Previously, we have shown that extracellular S100A4 binds to RAGE in articular chondrocytes and activates the RAGE signaling cascade leading to increased production of MMP-13 (5). Recent studies have shown that extracellular S100A4 can induce upregulation of several MMPs such as MMP-1, MMP-3, MMP-9 and MMP-13 in rheumatoid arthritis synovial fibroblasts (15). Taken together these studies suggest that S100A4 may play an important role in cartilage degradation and progression of arthritis.

IL-7 was initially identified as a factor required for the growth of murine B cell precursors (16). However, subsequent studies have shown that IL-7 plays an important role in T cell, dendritic cell, and bone biology in humans (17). IL-7 has been studied in rheumatoid arthritis (RA) due its elevated levels in serum from RA patients (18) and due to its increased expression in RA synovium and synovial fibroblast (SF) (19). Recently, we have found that IL-7 is expressed in chondrocytes and its expression is upregulated in OA chondrocytes and in normal chondrocytes with age (20). In addition, we also found that IL-7 expression was increased in chondrocytes in response to fibronectin fragment (Fn-F) and IL-1 stimulation and chondrocytes respond to IL-7 treatment with increased production of MMP-13 (20). These data suggest that IL-7 may play an important role in the cartilage degradation seen in $\mathrm{OA}$ as well as RA.

As discussed above, studies have shown that S100A4 is secreted into the extracellular environment (21), however the mechanism of secretion is not known. Thus, the current study was designed to determine if cytokines known to be active in cartilage can stimulate S100A4 secretion and study the pathway involved in this process. Experiments were carried out using human articular chondrocytes treated with different chemical inhibitors to define the involvement of cell signaling pathways, protein expression and protein secretion. The data presented here demonstrate that chondrocytes secrete S100A4 in response to IL-7 activation of the JAK/STAT signaling pathway.

\section{MATERIAL AND METHODS}

\section{Materials}

Recombinant human IL-1 $\beta$, IL-6, soluble IL-6 receptor, IL-7, IL-8 and the human proMMP-13 ELISA were purchased from R\&D systems (Minneapolis, MN). Human S100A4 antibody was purchased from Dako (Carpinteria, CA). JAK-3 and STAT-3 antibodies were from Santa Cruz Biotechnology (Santa Cruz, CA). Cycloheximide was purchased from Sigma (St.Louis, MO). JAK-3 inhibitor (WHI-P154) and brefeldin A were from Calbiochem (La Jolla, CA). Pronase was purchased from Calbiochem (San Diego, CA) and Collagenase P from Boehringer (Mannheim, Germany). An RNeasy mini kit was obtained from Qiagen 
(Valencia, CA). S100A4 and GAPDH primers and SybrGreen PCR mastermix were from Super Array Biosciences (Frederick, MD). Nitrocellulose membranes and ECL chemiluminescence detection kits were purchased from Amersham Biosciences (Piscataway, $\mathrm{NJ}$ ). Cell culture media and supplements were purchased from Gibco BRL (Gaithersburg, $\mathrm{MD})$.

\section{Tissue acquisition and chondrocyte cell culture}

Human ankle cartilage was obtained from tissue donors within 48 hours of death through the National Disease Research Interchange (Philadelphia, PA) in accordance with institutional protocol. Chondrocytes were isolated from normal cartilage by sequential digestion with Pronase and then overnight with collagenase, as previously described (22). Viability of isolated cells was determined using trypan blue, and cells were counted using a hemocytometer. Monolayer cultures were established by plating cells in 6- well plates at $2 \times 10^{6}$ cells/ml in Dulbecco's modified Eagle's medium (DMEM)/Ham's F-12 medium supplemented with $10 \%$ fetal bovine serum. Plates were maintained for 5-7 days, with feedings every 2 days until they reached $100 \%$ confluence prior to experimental use.

\section{Chondrocyte stimulation and immunoblotting}

Confluent primary chondrocyte monolayers were made serum-free overnight before treating with $10 \mathrm{ng} / \mathrm{ml}$ each of the cytokines IL-1, IL-6 (in combination with $20 \mathrm{ng} / \mathrm{ml}$ soluble IL-6 receptor), IL-7 or IL-8. Cells were incubated with these cytokines for 16-18 hours to examine for secretion of S100A4 or for 0-60 mins to study the activation of signaling proteins. For inhibition studies, cells were pretreated for 45-90 minutes with inhibitors before incubating with cytokines. Inhibitors tested included $10 \mathrm{mM}$ of a JAK-3 inhibitor, $10 \mu \mathrm{g} / \mathrm{ml}$ of cycloheximide and $1 \mu \mathrm{g} / \mathrm{ml}$ of brefeldin A. After incubation, conditioned medium was collected and analyzed for S100A4 by immunoblotting and for MMP-13 by ELISA. For signaling studies, cells were washed with PBS and lysed with lysis buffer that contained $20 \mathrm{~m} M$ Tris (pH 7.5), $150 \mathrm{~m} M \mathrm{NaCl}, 1 \mathrm{~m} M$ EDTA, $1 \mathrm{~m} M$ EGTA, $1 \%$ Triton $\mathrm{X}-100,2.5 \mathrm{~m} M$ tetra-pyrophosphate, $1 \mathrm{~m} M$ glycerol phosphate, $1 \mathrm{~m} M$ Na3VO4, $1 \mu \mathrm{l} / \mathrm{ml}$ leupeptin, and $1 \mathrm{~m} M$ phenylmethylsulfonyl fluoride. Lysates were centrifuged to remove insoluble material, and the soluble protein concentration was determined with BCA reagent (Pierce). Samples containing equal amounts of total protein were separated by sodium dodecyl sulfate-polyacrylamide gel electrophoresis (SDS-PAGE), transferred to nitrocellulose, and probed for signaling proteins. Immunoreactive bands were detected using the ECL system. All immunoblotting experiments were repeated at least 3 times with similar results.

\section{Real Time PCR analysis}

Total RNA was isolated using the RNeasy Mini Kit (Qiagen, Valencia, CA). Two micrograms of RNA was reverse transcribed using an AMV reverse transcriptase and oligo dT primer at $42^{\circ} \mathrm{C}$ for 1 hour. $2 \mu \mathrm{L}$ of RT reaction was then combined in a reaction mixture with $1 \mu \mathrm{L}$ of S100A4 specific primer pair (forward: 5'-TCTTTCTTGGTTTGATCCTG-3', reverse: 5'-GCATCAAGCACGTGTCTGAA-3'), 12.5 $\mu \mathrm{L} 2 \mathrm{X}$ SybrGreen PCR mastermix, and water to a final reaction volume of $25 \mu \mathrm{L}$. Reactions were then run in triplicate with 40 cycles of amplification on an ABI Prism 7000 real-time PCR machine (Applied Biosystems). A negative control was included, which contained primers, water and mastermix, but no cDNA. An amplification plot was generated using the ABI software. PCR specificity was confirmed by dissociation curve analysis. 


\section{STAT-3 activation analysis}

STAT-3 DNA binding activity was measured by using the ELISA-based Trans-AM transcription factor kits (Active Motif, Carlsbad, USA) according to the manufacturer's protocol. The primary antibody used to detect activated STAT-3 recognizes a specific epitope on STAT-3 that is accessible only when STAT-3 is activated and bound to its target DNA. In brief, after stimulation with IL-7, nuclear extracts were prepared and the activated STAT-3 in the extracts was captured on the ELISA plate pre-coated with oligonucleotides that correspond to STAT-3 consensus sequence binding sites (5' TTCCCGGAA-3') and detected with an HRP-conjugated secondary antibody.

\section{Analysis of MMP-13 production}

Conditioned medium obtained after 16-18 hrs of treatment with IL-7 from various experiments was collected and analyzed for MMP-13 by ELISA (R\& D systems) according to the manufacturer's protocol using duplicate wells for each sample. Samples were diluted (if needed) with culture medium to get the value within the linear range of the assays.

\section{Chondrocyte survival assay}

Chondrocytes survival was measured using LIVE/DEAD cell survival assay (Molecular Probes, Eugene, OR) as described previously (23).

\section{Statistical analysis}

Data sets were analyzed by ANOVA using StatView 5.0 (SAS Institute Inc., Cary, NC, USA).

\section{Dominant-negative RAGE transfection}

Chondrocytes were transfected by the nucleofection method using human chondrocyte nucleofection kit (Amaxa Biosystems, Gaithersburg, MD, U.S.A.) described earlier (24). In brief, isolated cells were resuspended in transfection reagent and nucleofected with $2 \mu \mathrm{g}$ of plasmid DNA expressing dominant negative RAGE (DN-RAGE) (generous gift from Dr. Shi Du Yan, Columbia University, New York). After the recovery period of $48 \mathrm{hrs,} \mathrm{cells}$ were made serum free over night prior to stimulation with IL-7 and subsequent measurement of MMP-13 as detailed above.

\section{RESULTS}

\section{IL-7 promotes secretion and expression of S100A4 by human articular chondrocytes}

To examine if articular chondrocytes secret S100A4, cells were treated with IL-1, IL-6, IL-7, or IL-8 $(10 \mathrm{ng} / \mathrm{ml})$ for $16-18 \mathrm{hrs}$ and the presence of S100A4 protein in the conditioned media was examined by immunoblotting. This revealed an immunoreactive band corresponding to a molecular mass of $11 \mathrm{kD}$ in the conditioned media obtained from the treatment with IL-6, IL-7 or IL-8. However, the intensity of the immunoreactive band was stronger in the media samples obtained after IL-7 treatment compared to the other cytokines (Fig 1A). Immunoblots from 3 independent experiments were quantified and demonstrated a significant increase in S100A4 in response to IL-7 stimulation (Fig 1B). Analysis of cell lysates by immunoblotting did not show any significant change in the intracellular S100A4 protein levels upon treatment with any of the above cytokines (Fig 1C) suggesting that the increase in the media in response to IL-7 was due to secretion accompanied by increased expression such that the intracellular levels were stable. Alternatively, treatment of chrondrocytes with IL-7 may have promoted stability or inhibited reuptake of S100A4 resulting in increased levels in the media. 
In order to study the expression of S100A4 further, we examined if IL-7 would induce S100A4 mRNA expression. Total RNA isolated from the chondrocytes stimulated with IL-7 for 16-18 hrs showed increased expression of S100A4 mRNA as analyzed by real time PCR (Fig 1D). This finding suggests that increased production of S100A4 kept pace with secretion resulting in stable intracellular levels of S100A4.

\section{Effect of cycloheximide and brefeldin A on IL-7 mediated S100A4 secretion}

Since our data showed that IL-7 induced both S100A4 secretion and mRNA expression in chondocytes, we wanted to examine if de novo protein synthesis is required for the increase in extracellular S100A4. Pretreatment of chondrocytes with cycloheximide, a chemical inhibitor of protein synthesis, followed by treatment with IL-7 reduced the amount of S100A4 secreted by chondrocytes (Fig 2A). To ensure that the decrease in S100A4 secretion observed in chondrocytes treated with cycloheximide was not due to cytotoxicity, we performed a cell survival assay and did not observe any cell death at the concentration or the duration of incubation period used in our experimental conditions (data not shown).

To further understand the molecular mechanism of S100A4 secretion by chondrocytes, we used brefeldin A, a chemical compound that blocks protein translocation from the endoplasmic reticulum (ER) to the Golgi complex (25). Pretreatment of the chondrocytes with brefeldin A, followed by stimulation with IL-7 did not block the secretion of S100A4 (Fig 2B). The data suggests that the secretion of S100A4 in chondrocytes follows an alternative pathway of protein secretion independent of classical ER-Golgi pathway. Interestingly, treatment of chondrocytes with brefeldin A reduced the secretion of MMP-2 protein, which we have been using as our loading control.

\section{Role of the JAK/STAT signaling pathway in S100A4 secretion}

Studies have shown that IL-7 can activate the JAK (receptor-associated tyrosine Janus kinases) / STAT (signal transducers and activators of transcription) signaling pathway (26). Thus, we were interested in examining the role of JAK/STAT signaling in the secretion of S100A4 by chondrocytes. Stimulation of normal chondrocytes with IL-7 induced increased phosphorylation of JAK-3 and STAT-3 in a time dependent manner, with a significant increase observed in phosphorylation of JAK-3 within 15 minutes, and maximal increase over control levels observed after 60 minutes (Fig 3A). The phosphorylation of STAT-3 was more transient with a decline in phosphorylation observed within 45 minutes. In addition, we also observed delayed phosphorylation of JAK-1 upon IL-7 stimulation in chondrocytes (data not shown). The increased phosphorylation of STAT-3 correlated with increased DNA binding activity of STAT-3 (Fig 3B).

Pretreatment of normal chondrocytes with a JAK-3 inhibitor blocked the phosphorylation of both JAK-3 and STAT-3 (Fig 3C) and the DNA binding activity of STAT-3 (Fig 3D).

Additionally, pretreatment of normal chondrocytes with a JAK-3 inhibitor blocked the IL-7 mediated secretion of S100A4 (Fig 4). Taken together these data suggest that activation of JAK/STAT pathway is essential for the IL-7-mediated secretion of S100A4 by chondrocytes.

\section{IL-7 stimulates increased production of MMP-13 by chondrocytes via S100A4 binding to RAGE}

We have previously shown that treatment of chondrocytes with extracellular S100A4 resulted in increased production of MMP-13 through the activation of RAGE (5). Since treatment of normal chondrocytes with IL-7 resulted in the secretion of S100A4, we were interested in examining the relationship between the IL-7 mediated secretion of S100A4 and increased production of MMP-13. Treatment of chondrocytes with IL-7 resulted in increased 
production of MMP-13 in the conditioned media (Fig 5A). Pretreatment of cells with the JAK-3 inhibitor blocked the increased production of MMP-13 (Fig 5A) suggesting that the increased production of MMP-13 observed in response to IL-7 required activation of the JAK/STAT pathway as was found for IL-7 mediated S100A4 secretion. Pretreatment of cells with the JAK-3 inhibitor but without IL-7 did not have any effect on the production of MMP-13 (data not shown).

Since RAGE has been previously shown to mediate MMP-13 production by S100A4 (5), we examined its role in IL-7 mediated production of MMP-13. Overexpression of dominant negative RAGE (DN-RAGE) in chondrocytes not only blocked the ability of IL-7 to stimulate chondrocyte MMP-13 production (Fig 5B) it also reduced the basal level of MMP-13 production (Fig 5B). This suggests that both IL-7 mediated MMP-13 production and some of the basal production of MMP-13 by chondrocytes required RAGE.

\section{DISCUSSION}

Members of the S100 family of calcium binding proteins are unique in having both intracellular and extracellular functions. S100 proteins lack the classical signaling sequence for secretion yet are released into the extracellular environment. The molecular mechanism of secretion of these proteins is poorly understood. In the current study, we show that S100A4 is secreted by human articular chondrocytes in response to IL-7 stimulation and activation of the JAK/STAT pathway is required. IL-7 mediated S100A4 secretion can then act in an autocrine fashion to stimulate MMP-13 production via RAGE.

We have recently identified IL-7 in chondrocytes and shown that IL-7 is produced by chondrocytes in response to fibronectin fragment (Fn-F) and IL-1 $\beta$ stimulation (20). In the current study, we show that treatment of human articular chondrocytes with IL-7 resulted in an increase in both mRNA expression and secretion of S100A4. Pretreatment of chondrocytes with cycloheximide abolished the IL-7 mediated secretion of S100A4 suggesting that the S100A4 mRNA expression and de novo protein synthesis play an important role in IL-7 mediated secretion of S100A4 by chondrocytes. However, pretreatment of chondrocytes with brefeldin A did not have any effect on the IL-7 mediated secretion of S100A4 suggesting that the secretion of S100A4 in chondrocytes does not follow the ER-Golgi secretory pathway. Previous studies on other members of the S100 family of proteins have likewise demonstrated an alternate secretory pathway, independent of the classical ER-Golgi route $(27,28)$ and the requirement for de novo protein synthesis (29).

Earlier studies have shown that members of the $\mathrm{S} 100$ family of proteins can be secreted in response to external stimuli that activate signaling proteins such as protein kinase $\mathrm{C}$, (PKC) $(27,28)$ or ERK1/2 $(30)$. In the current study, IL-7 signaling required phosphorylation of JAK-3 and the downstream transcription factor STAT-3 which resulted in increased DNA binding activity of the STAT. In addition, our studies also showed a delayed phosphorylation of JAK-1. Studies have shown that JAK-3 is constitutively associated with the carboxy-terminal region of the $\gamma c$ component of the IL-7-receptor and activation of JAK-3 is considered to be the first step in the signal transduction cascade induced by IL-7 binding (27). Activation of JAK-3 is followed by phosphoryation of JAK-1 which is associated with $\alpha$-chain of the receptor, and which then leads to the recruitment of STAT protein $(31,32)$. Activated STATs translocate into the nucleus and activate their target genes $(33,34)$.

Previous studies have shown that the JAK/STAT pathway is operative in chondrocytes. Stimulation of chondrocytes with oncostatin (OSM) resulted in the increased 
phosphorylation of JAK-3 and increased DNA binding activity of STAT-1. Inhibition of this signaling pathway by a JAK-3 inhibitor blocked the OSM induced MMP-1, MMP-3 and MMP-13 gene expression in chondrocytes (35). Additionally, in support of our observation, a recent study has shown that IL-7 can stimulate increased phosphorylation of PYK-2, a non-receptor tyrosine kinase and member of focal adhesion kinase family in chondrocytes (20). Studies have previously shown that PYK-2 is activated by IL-7 via a JAK signaling pathway (36) and PYK-2 was found in association with JAK-3, thus implicating PYK-2 as an important component of the JAK/STAT signaling pathway (37). Taken together, these studies suggest an important role for IL-7 mediated JAK/STAT signaling in the secretion of S100A4 by chondrocytes.

Treatment of chondrocytes with IL-7 also resulted in the induction of MMP-13 production in conditioned media, which is consistent with our earlier report (20). Pretreatment of chondroyctes with a JAK-3 inhibitor blocked both the IL-7 mediated secretion of S100A4 and production of MMP-13 suggesting a relationship between secretion of S100A4 and production of MMP-13 with IL-7. Previously, we have shown that stimulation of MMP-13 production by extracellular S100A4 required activation of RAGE signaling (5). In the present study, transient overexpression of DN-RAGE (dominant negative RAGE) in chondrocytes blocked the IL-7 mediated production of MMP-13 consistent with the hypothesis that S100A4 released by the chondrocytes in response to IL-7 stimulation functions as an autocrine or paracrine factor to induce MMP-13 production via RAGE activation.

In summary, our data showed that IL-7 stimulates chondrocyte secretion of S100A4 via activation of the JAK/STAT signaling pathway. Extracellular S100A4 then functions as an autocrine factor and stimulates MMP-13 production via RAGE. Previous studies have shown that S100A4, RAGE and IL-7 are increased in OA cartilage. Thus, IL-7 and S100A4 may contribute to cartilage destruction and development of OA.

\section{Acknowledgments}

We are grateful to the National Disease Research Interchange (Philadelphia, PA) for providing normal tissue and Mary Zhao for technical assistance. This work was supported by research grants from the American Federation for Aging Research (RRY), NIH/NIA AG-16697 (RFL) and NIH/NIA P30-AG21332 (Wake Forest University Claude D Pepper Older Americans Independence Center).

\section{REFERENCES}

1. Donato R. S100: a multigenic family of calcium-modulated proteins of the EF-hand type with intracellular and extracellular functional roles. Int. J. Biochem. Cell Biol. 2001; 33:637-668. [PubMed: 11390274]

2. Santamaria-Kisiel L, Rintala-Dempsey AC, Shaw GS. Calcium-dependent and -independent interactions of the S100 protein family. Biochem J. 2006; 396:201-214. [PubMed: 16683912]

3. Huttunen HJ, Kuja-Panula J, Sorci G, Agneletti AL, Donato R, Rauvala H. Coregulation of neurite outgrowth and cell survival by amphoterin and S100 proteins through receptor for advanced glycation end products (RAGE) activation. J. Biol. Chem. 2000; 275:40096-40105. [PubMed: 11007787]

4. Heizmann CW, Ackermann GE, Galichet A. Pathologies involving the S100 proteins and RAGE. Subcell Biochem. 2007; 45:93-138. [PubMed: 18193636]

5. Yammani RR, Carlson CS, Bresnick AR, Loeser RF. Increase in production of matrix metalloproteinase 13 by human articular chondrocytes due to stimulation with S100A4: Role of the receptor for advanced glycation end products. Arthritis Rheum. 2006; 54:2901-2911. [PubMed: 16948116] 
6. Cecil DL, Johnson K, Rediske J, Lotz M, Schmidt AM, Terkeltaub R. Inflammation-induced chondrocyte hypertrophy is driven by receptor for advanced glycation end products. J Immunol. 2005; 175:8296-8302. [PubMed: 16339570]

7. Ebralidze A, Tulchinsky E, Grigorian M, Afanasyeva A, Senin V, Revazova E, et al. Isolation and characterization of a gene specifically expressed in different metastatic cells and whose deduced gene product has a high degree of homology to a Ca2+-binding protein family. Genes Dev. 1989; 3:1086-1093. [PubMed: 2550322]

8. Takenaga K, Nakamura Y, Sakiyama S. Cellular localization of pEL98 protein, an S100-related calcium binding protein, in fibroblasts and its tissue distribution analyzed by monoclonal antibodies. Cell Struct Funct. 1994; 19:133-141. [PubMed: 7954872]

9. Klingelhöfer J, Senolt L, Baslund B, Nielsen GH, Skibshøj I, Pavelka K, Neidhart M, Gay S, Ambartsumian N, Hansen BS, Petersen J, Lukanidin E, Grigorian M. Up-regulation of metastasispromoting S100A4 (Mts-1) in rheumatoid arthritis: putative involvement in the pathogenesis of rheumatoid arthritis. Arthritis Rheum. 2007; 56:779-789. [PubMed: 17328050]

10. Grigorian M, Andresen S, Tulchinsky E, Kriajevska M, Carlberg C, Kruse C, et al. Tumor suppressor $\mathrm{p} 53$ protein is a new target for the metastasis-associated Mts1/S100A4 protein: functional consequences of their interaction. J Biol Chem. 2001; 276:22699-22708. [PubMed: 11278647]

11. Li ZH, Spektor A, Varlamova O, Bresnick AR. Mts1 regulates the assembly of non-muscle myosin-IIA. Biochemistry. 2003; 42:14258-14266. [PubMed: 14640694]

12. Novitskaya V, Grigorian M, Kriajevska M, Tarabykina S, Bronstein I, Berezin V, et al. Oligomeric forms of the metastasis-related Mts1 (S100A4) protein stimulate neuronal differentiation in cultures of rat hippocampal neurons. J Biol Chem. 2000; 275:41278-41286. [PubMed: 11018041]

13. Ambartsumian N, Klingelhofer J, Grigorian M, Christensen C, Kriajevska M, Tulchinsky E, et al. The metastasis-associated Mts1 (S100A4) protein could act as an angiogenic factor. Oncogene. 2001; 20:4685-4695. [PubMed: 11498791]

14. Bjornland K, Winberg JO, Odegaard OT, Hovig E, Loennechen T, Aasen AO, et al. S100A4 involvement in metastasis: deregulation of matrix metalloproteinases and tissue inhibitors of matrix metalloproteinases in osteosarcoma cells transfected with an anti-S100A4 ribozyme. Cancer Res. 1999; 59:4702-4708. [PubMed: 10493528]

15. Senolt L, Grigorian M, Lukanidin E, Simmen B, Michel BA, Pavelka K, Gay RE, Gay S, Neidhart M. S100A4 is expressed at site of invasion in rheumatoid arthritis synovium and modulates production of matrix metalloproteinases. Ann Rheum Dis. 2006; 65:1645-1648. [PubMed: 17105852]

16. Namen AE, Lupton S, Hjerrild K, Wignall J, Mochizuki DY, Schmierer A, Mosley B, March CJ, Urdal D, Gillis S. Stimulation of B-cell progenitors by cloned murine interleukin-7. Nature. 1988; 333:571-573. [PubMed: 3259677]

17. Churchman SM, Ponchel F. Interleukin-7 in rheumatoid arthritis. Rheumatology. 2008; 47:753759. [PubMed: 18356170]

18. Hartgring SA, Wenting MJ, Jacobs KM, Bijlsma JW, Lafeber FP, van Roon JA. IL-7-induced immune activation due to elevated expression of the IL-7 receptor in RA joints can be inhibited by soluble human IL-7 receptor. Arthritis Rheum. 2007; 56:1991.

19. Harada S, Yamamura M, Okamoto H, Morita Y, Kawashima M, Aita T, Makino H. Production of interleukin-7 and interleukin-15 by fibroblast-like synoviocytes from patients with rheumatoid arthritis. Arthritis Rheum. 1999; 42:1508-1516. [PubMed: 10403280]

20. Long D, Blake S, Song XY, Lark M, Loeser RF. Human articular chondrocytes produce IL-7 and respond to IL-7 with increased production of matrix metalloproteinase-13. Arthritis Res Ther. 2008; 10:R23. [PubMed: 18289383]

21. Schmidt-Hansen B, Klingelhofer J, Grum-Schwensen B, Christensen A, Andresen S, Kruse C, Hansen T, Ambartsumian N, Lukanidin E, Grigorian M. Functional Significance of Metastasisinducing S100A4 (Mts1) in Tumor-Stroma Interplay. J. Biol. Chem. 2004; 279:24498-24504. [PubMed: 15047714]

22. Forsyth CB, Pulai J, Loeser RF. Fibronectin fragments and blocking antibodies to $\alpha 2 \beta 1$ and $\alpha 5 \beta 1$ integrins stimulate mitogenactivated protein kinase signaling and increase collagenase 3 (matrix 
metalloproteinase 13) production by human articular chondrocytes. Arthritis Rheum. 2002; 46:2368-2376. [PubMed: 12355484]

23. Del Carlo M Jr, Loeser RF. Nitric oxide-mediated chondrocyte cell death requires the generation of additional reactive oxygen species. Arthritis Rheum. 2002; 46:394-403. [PubMed: 11840442]

24. Loeser RF, Yammani RR, Carlson CS, Chen H, Cole A, Im HJ, et al. Articular chondrocytes express the receptor for advanced glycation end products: potential role in osteoarthritis. Arthritis Rheum. 2005; 52:2376-2385. [PubMed: 16052547]

25. Misumi Y, Misumi Y, Miki K, Takatsuki A, Tamura G, Ikehara Y. Novel blockade by brefeldin A of intracellular transport of secretory proteins in cultured rat hepatocytes. J Biol Chem. 1986; 261:11398-11403. [PubMed: 2426273]

26. Jiang Q, Li WQ, Aiello FB, Mazzucchelli R, Asefa B, Khaled AR, Durum SK. Cell biology of IL-7, a key lymphotrophin. Cytokine Growth Factor Rev. 2005; 16:513-533. [PubMed: 15996891]

27. Hasegawa T, Kosaki A, Kimura T, Matsubara H, Mori Y, Okigaki M, Masaki H, Toyoda N, InoueShibata M, Kimura Y, Nishikawa M, Iwasaka T. The regulation of EN-RAGE (S100A12) gene expression in human THP-1 macrophages. Atherosclerosis. 2003; 171:211-218. [PubMed: 14644389]

28. Rammes A, Roth J, Goebeler M, Klempt M, Hartmann M, Sorg C. Myeloid-related protein (MRP) 8 and MRP14, calcium-binding proteins of the S100 family, are secreted by activated monocytes via a novel, tubulin-dependent pathway. J Biol Chem. 1997; 272:9496-9502. [PubMed: 9083090]

29. Hsieh HL, Schäfer BW, Cox JA, Heizmann CW. S100A13 and S100A6 exhibit distinct translocation pathways in endothelial cells. J Cell Sci. 2002; 115:3149-3158. [PubMed: 12118070]

30. Lawrie A, Spiekerkoetter E, Martinez EC, Ambartsumian N, Sheward WJ, MacLean MR, Harmar AJ, Schmidt AM, Lukanidin E, Rabinovitch M. Interdependent serotonin transporter and receptor pathways regulate S100A4/Mts1, a gene associated with pulmonary vascular disease. Circ Res. 2005; 97:227-235. [PubMed: 16002749]

31. O'Shea JJ, Gadina M, Schreiber RD. Cytokine signaling in 2002: new surprises in the Jak/Stat pathway. Cell. 2002; 109:S121-S131. [PubMed: 11983158]

32. Qin JZ, Kamarashev J, Zhang CL, Dummer R, Burg G, Döbbeling U. Constitutive and interleukin-7- and interleukin-15-stimulated DNA binding of STAT and novel factors in cutaneous T cell lymphoma cells. J Invest Dermatol. 2001; 117:583-589. [PubMed: 11564163]

33. Foxwell BM, Beadling C, Guschin D, Kerr I, Cantrell D. Interleukin-7 can induce the activation of Jak 1, Jak 3 and STAT 5 proteins in murine T cells. Eur J Immunol. 1995; 25:3041-3046. [PubMed: 7489741]

34. van der Plas DC, Smiers F, Pouwels K, Hoefsloot LH, Löwenberg B, Touw IP. Interleukin-7 signaling in human B cell precursor acute lymphoblastic leukemia cells and murine BAF3 cells involves activation of STAT1 and STAT5 mediated via the interleukin-7 receptor alpha chain. Leukemia. 1996; 10:1317-1325. [PubMed: 8709637]

35. Li WQ, Dehnade F, Zafarullah M. Oncostatin M-induced matrix metalloproteinase and tissue inhibitor of metalloproteinase-3 genes expression in chondrocytes requires Janus kinase/STAT signaling pathway. J Immunol. 2001; 166:3491-3498. [PubMed: 11207308]

36. Benbernou N, Muegge K, Durum SK. Interleukin (IL)-7 induces rapid activation of Pyk2, which is bound to Janus kinase 1 and IL-7Ralpha. J Biol Chem. 2000 Mar 10.275:7060-7065. [PubMed: 10702271]

37. Miyazaki T, Takaoka A, Nogueira L, Dikic I, Fujii H, Tsujino S, Mitani Y, Maeda M, Schlessinger $\mathrm{J}$, Taniguchi T. Pyk2 is a downstream mediator of the IL-2 receptor-coupled Jak signaling pathway. Genes Dev. 1998; 12:770-775. [PubMed: 9512511] 


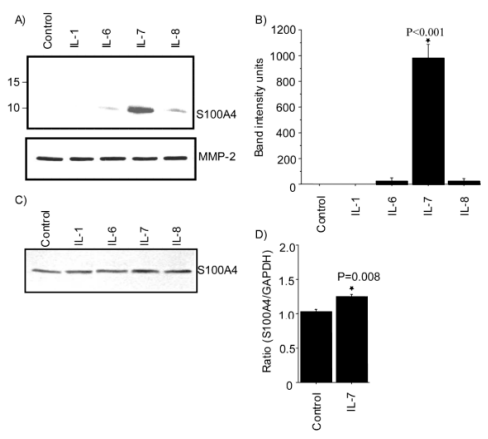

Figure 1. IL-7 stimulates S100A4 production by chondrocytes

Human articular chondrocytes were isolated from normal cartilage and cultured as monolayers. Cells in serum-free confluent culture were treated with $(10 \mathrm{ng} / \mathrm{ml})$ human recombinant IL-1, -6, -7 or IL-8 for 16-18 hrs. A. Secretion of S100A4 into the media was measured by immunoblotting with human anti-S100A4. Blots were striped and re-probed with anti-human MMP-2 as a loading control. B. Densitometric analysis was performed on blots obtained in three independent experiments similar to the one shown in panel A. Results shown are the mean and SEM (* p<0.001 vs control, IL-1, IL-6 and IL-8). C. Intracellular S100A4 protein level was measured in cell lysates by immunoblotting D. Total RNA was prepared and expression of mRNA for S100A4 and GAPDH (control for normalization) was analyzed by real time PCR using specific primers for S100A4 and GAPDH. The results shown are the mean and SEM derived from three independent experiments. 


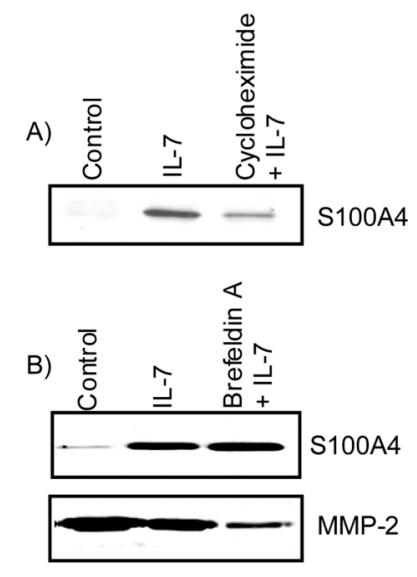

Figure 2. Effect of cycloheximide and brefeldin on the secretion of S100A4 by chondrocytes Cultured chondrocytes were pretreated with or without $10 \mu \mathrm{g} / \mathrm{ml}$ of cycloheximide for 90 minutes (A) or $1 \mu \mathrm{g} / \mathrm{ml}$ brefeldin A for 60 minutes (B) followed by stimulation with $10 \mathrm{ng} / \mathrm{ml}$ of IL-7 for 16-18 hrs. Secretion of S100A4 into the media was examined by immunoblotting with anti S100A4 antibody. Blots were stripped and reprobed with antihuman MMP-2 as a loading control. 

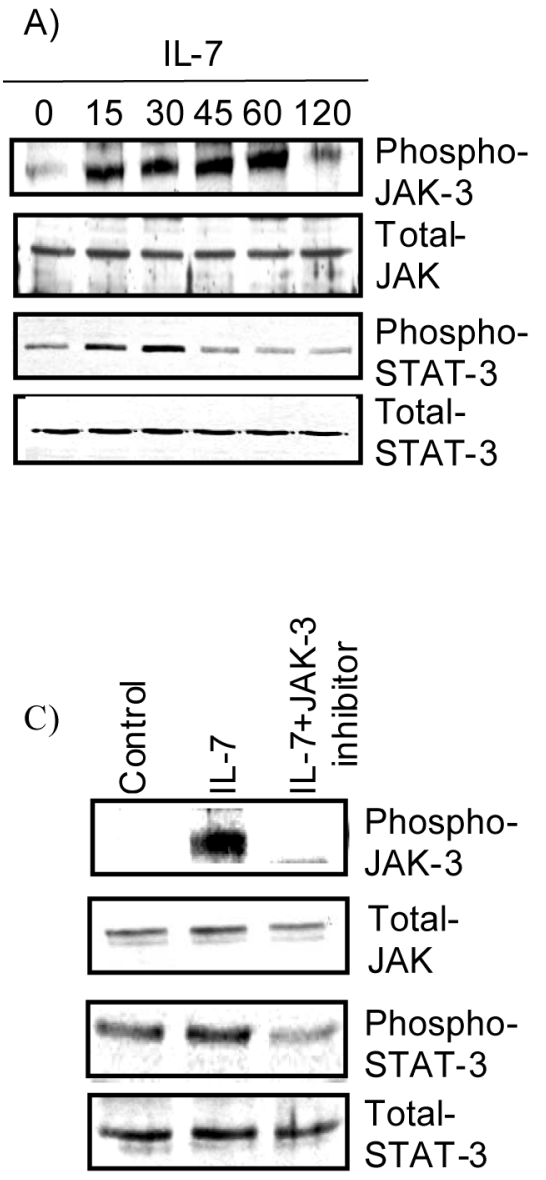
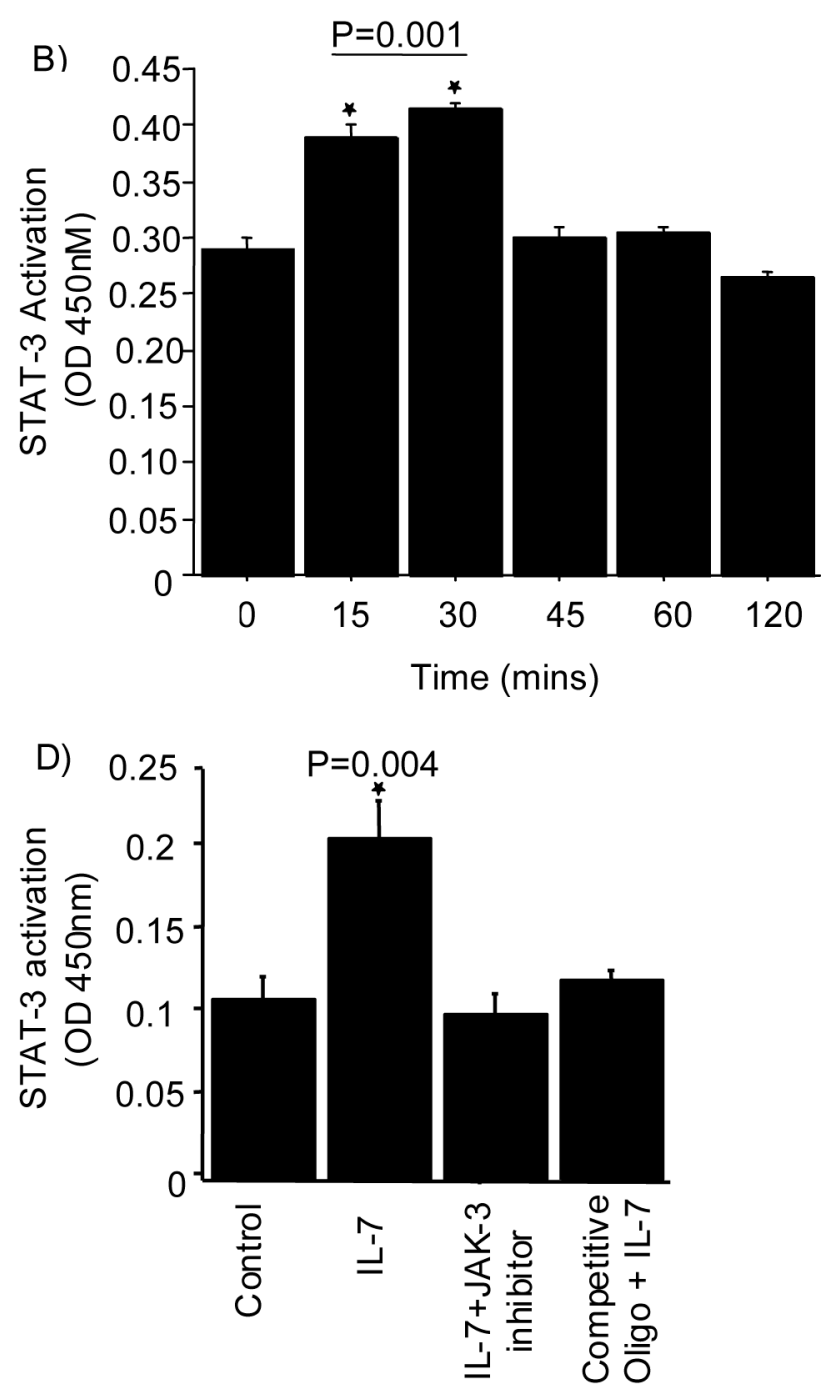

Figure 3. Activation of the JAK/STAT pathway by IL-7

A. Chondrocytes in serum-free confluent monolayer cultures were stimulated with or without $10 \mathrm{ng} / \mathrm{ml}$ IL-7 for 0-120 minutes. The cell lysates were immunoblotted for the phosphorylated and total JAK-3 and STAT-3 signaling proteins. B. DNA binding activity of STAT-3 was measured in nuclear extracts by using the TransAM ELISA according to manufacturer's protocol. C. Chondrocytes were pretreated for 45 minutes with a JAK-3 inhibitor $(10 \mathrm{uM})$ before stimulation with IL-7. Cell lysates were immunoblotted for the phosphorylated and total JAK-3 and STAT-3 signaling proteins D. The DNA binding activity of STAT-3 was measured in the nuclear extracts following 30 minutes incubation with IL-7. Values in panel B and D are the mean and SEM of three independent experiments. 


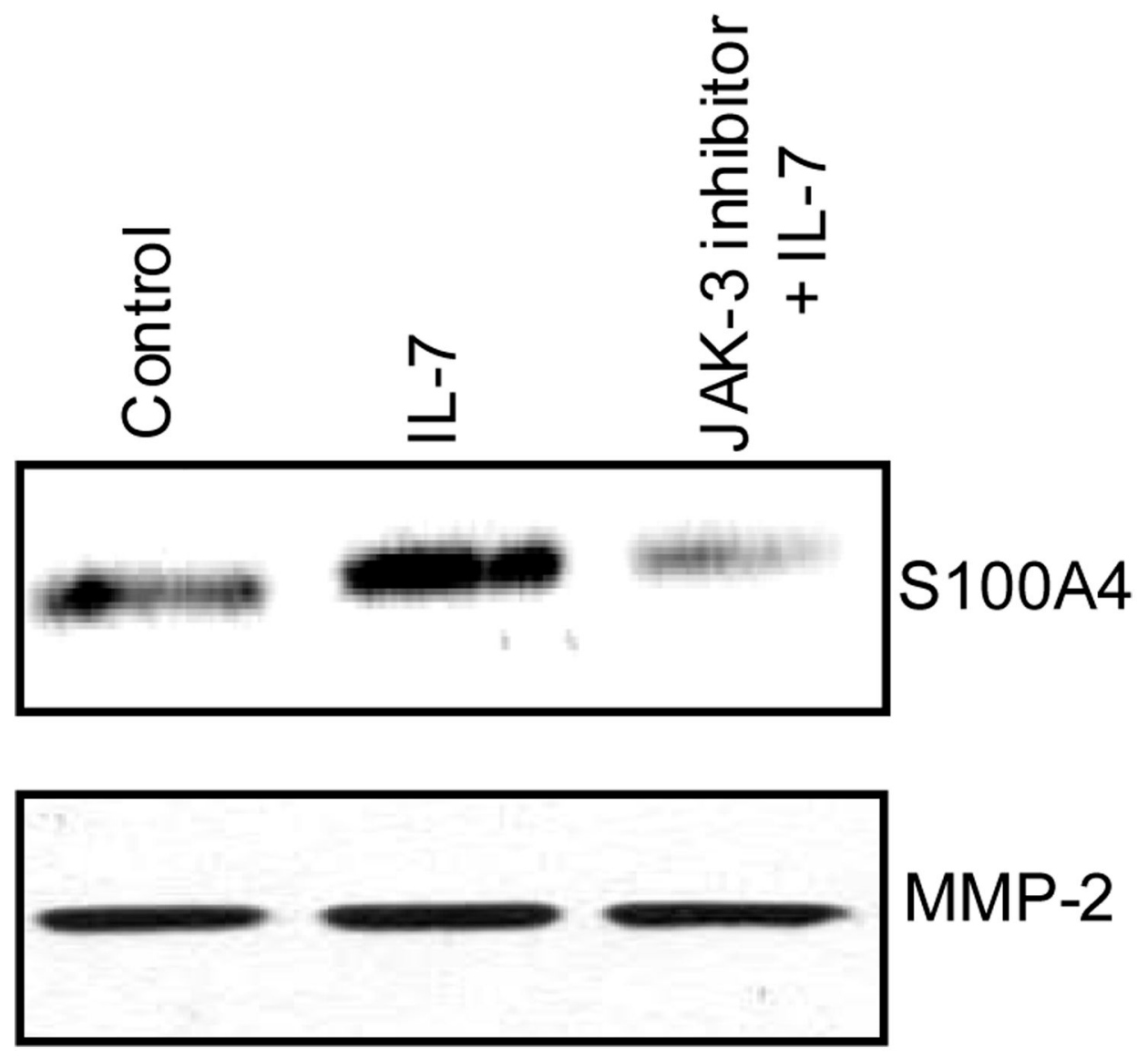

Figure 4. Effect of JAK-3 inhibitor on S100A4 secretion

Chondrocytes in serum-free medium were pre-treated with or without $10 \mathrm{uM} \mathrm{JAK}-3$ inhibitor for 45 minutes followed by stimulation with $10 \mathrm{ng} / \mathrm{ml} \mathrm{IL-7} \mathrm{for} \mathrm{16-18} \mathrm{hr.}$ Conditioned media obtained after the incubation period was analyzed for S100A4 by immunoblotting and for MMP-2 as a loading control. 
A)

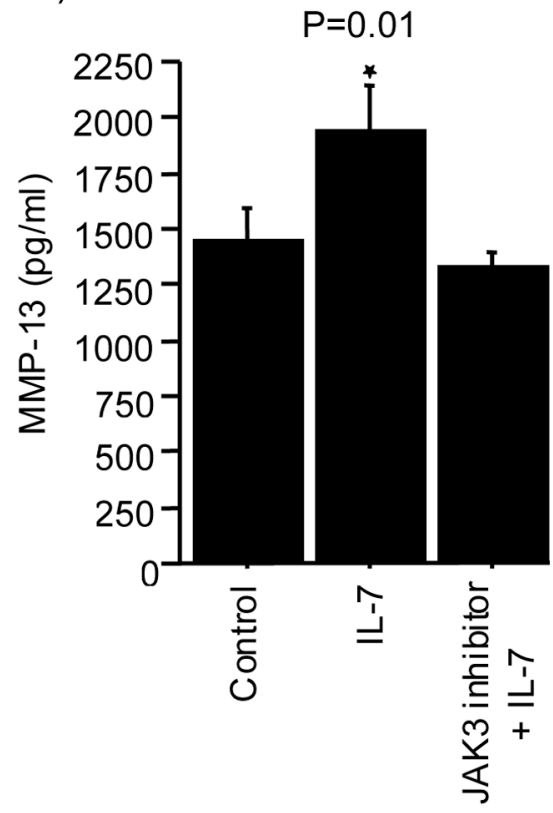

B)

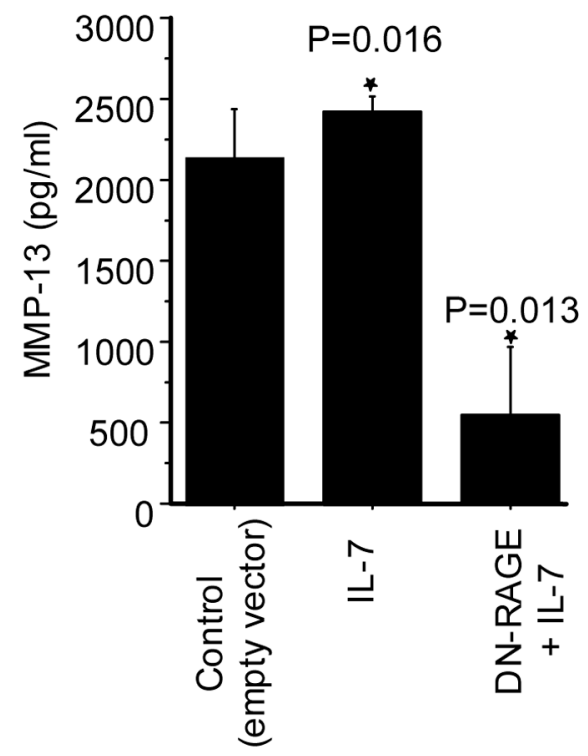

Figure 5. Role of JAK-3 and RAGE in the IL-7 mediated production of MMP-13

A. Chondrocytes were pre-treated with or without 10 uM JAK-3 inhibitor for 45 minutes followed by stimulation with $10 \mathrm{ng} / \mathrm{ml} \mathrm{IL-7} \mathrm{for} 16-18$ hours ( $\mathrm{P}=0.01$ vs control) B . Chondrocytes were transfected with or without a dominant-negative RAGE (DN-RAGE) construct and treated with IL-7 for 16-18 hours. Conditioned media obtained after the incubation period was analyzed for MMP-13 by ELISA. Values are the mean and SEM of three independent experiments $(\mathrm{P}=0.016$ corresponds to control vs IL- 7 and $\mathrm{P}=0.013$ to IL-7 vs DN-RAGE + IL-7). 